\title{
(2) Fifteen-minute consultation: OPEN ACCESS Practical use of continuous glucose monitoring
}

\author{
Astha Soni (D) ,' Neil Wright (D) ,' Juliana Chizo Agwu (D) , 3,4 \\ Josephine Drew, ${ }^{5}$ Melanie Kershaw, ${ }^{6}$ Christopher Moudiotis, ${ }^{7}$ \\ Fiona Regan, ${ }^{8}$ Eleri Williams, ${ }^{9}$ Alison Timmis, ${ }^{10}$ Sze May Ng (i) 11,12
}

For numbered affiliations see end of article.

\section{Correspondence to Dr Astha Soni, Paediatrics, Sheffield Children's Hospital, Sheffield, UK; a.soni1@nhs.net}

Received 11 January 2021 Revised 1 April 2021 Accepted 4 April 2021
Q Check for updates

(C) Author(s) (or their employer(s)) 2021. Re-use permitted under CC BY-NC. No commercial re-use. See rights and permissions. Published by BMJ.

To cite: Soni A, Wright $\mathrm{N}$, Agwu JC, et al. Arch Dis Child Educ Pract Ed Epub ahead of print: [please include Day Month Year]. doi:10.1136/ archdischild-2020-321190

\section{ABSTRACT}

Type 1 diabetes is a self-managed condition. Regular monitoring of blood glucose (BG) levels has been the cornerstone of diabetes management. Finger prick BG testing traditionally has been the standard method employed. More recently, rapid advancements in the development of continuous glucose monitoring devices have led to increased use of technology to help children and young people with diabetes manage their condition. These devices have the potential to improve diabetes control and reduce hypoglycaemia especially if used in conjunction with a pump to automate insulin delivery. This paper aims to provide an update on main CGM devices available and practical considerations for doctors if they come across a child with diabetes who is using one of these devices.

\section{INTRODUCTION}

Type 1 diabetes is a self-managed condition. Regular self-monitoring of blood glucose (SMBG) levels has been the cornerstone of diabetes management, with finger-prick blood glucose (BG) testing traditionally being the standard method employed. NICE guideline NG18 recommends a minimum of 5 tests a day for children and young people (CYP) with diabetes. ${ }^{1}$ Since the advent of intensive diabetes management regimes, frequent BG monitoring had been one consistent factor shown to improve glycaemic control. ${ }^{2}$ More recently, rapid advancements in the development of continuous glucose monitoring devices have led to increased use of technology to help CYP with diabetes manage their condition. These devices have the potential to improve diabetes control and reduce hypoglycaemia 'especially if used in conjunction with a pump to automate insulin delivery'. ${ }^{3}$ The availability of
CGM for all on the NHS might herald the end of capillary BG testing.

This paper aims to provide a summary of the main CGM devices available and practical considerations for any doctor coming across a child with diabetes who is using one of these devices.

\section{Case study 1}

A 5-year-old girl with Type 1 diabetes is admitted to the ward with an abscess. She is on intravenous antibiotics and likely to be going to the theatre for incision and drainage. You are the paediatric registrar on-call. The nurse looking after the child has called you to speak to his mother as she is reluctant to let the nurse check her BG regularly as suggested. Her mother explains that the child is wearing a CGM device so she can keep an eye on her glucose levels without needing to prick her finger. You have heard about a CGM device but not seen anybody using it before.

\section{WHAT DO YOU NEED TO KNOW ABOUT CGM?}

Continuous glucose monitoring systems are devices that are inserted subcutaneously and measure interstitial BG levels. There are three essential components to a CGM: a sensor to detect changes in glucose, which is a small flexible probe and sits in the interstitial space, a transmitter and a receiver. The electro enzymatic sensor containing glucose oxidase reacts in the presence of glucose to produce hydrogen peroxide and electrons. The electron signal produced is proportional to the interstitial fluid glucose level. The transmitter then sends the signal from the sensor to the receiver, and the receiver displays the glucose level (figure 1). Sensors usually detect glucose levels every 5-15 min. Some systems are 


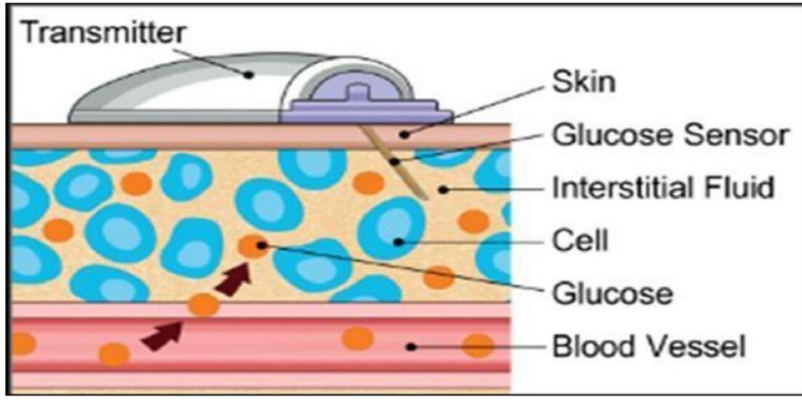

Figure 1 Diagrammatic representation of a continuous glucose monitoring device.

factory calibrated and others require regular user calibration, with the need to enter SMBG data every 12-24 hours.

There are two different types of CGM systems used in clinical practice.

\section{Real-time CGM}

These devices provide the user with glucose readings continuously, as they become available. They also have alarms/alerts for hyperglycaemia and hypoglycaemia, rates of glycaemic change and for predicting hypo/hyperglycaemia. Alarms can be customised to suit individual needs. Real-time CGM devices display the sensor glucose on a specific receiver and some have the ability to connect to smartphones or other devices.

\section{Intermittent glucose monitoring}

This device displays sensor glucose values only when scanned. FreeStyle Libre is the only such system available. The first generation Freestyle Libre does not have inbuilt alarms so lacks the ability to alert the user; however, the upgraded second-generation Libre 2 recently launched has in-built alarms.

The Libre sensor has an 8-hour memory and thus must be scanned at least every 8 hours. If it is not scanned within this time frame, the data are lost. The receiver can store data for up to 90 days. Some smart devices with near field communication technology can be used to scan the sensor. Libre 2, the most recent version of FreeStyle Libre, is a real-time CGM. Table 1 summarises the main characteristics of currently available CGM systems.

The child had a hypo $(\mathrm{BG}<4 \mathrm{mmol} / \mathrm{L})$ on the ward which was confirmed by fingerpick BG test. It was treated appropriately by the ward staff but they noticed that there is a discrepancy between the finger prick BG readings and CGM. Her BG came up to 5.5 $\mathrm{mmol} / \mathrm{L} 15 \mathrm{~min}$ after the treatment was given but the CGM value was displaying $4.5 \mathrm{mmol} / \mathrm{L}$. You notice that on the CGM display screen, the glucose level is

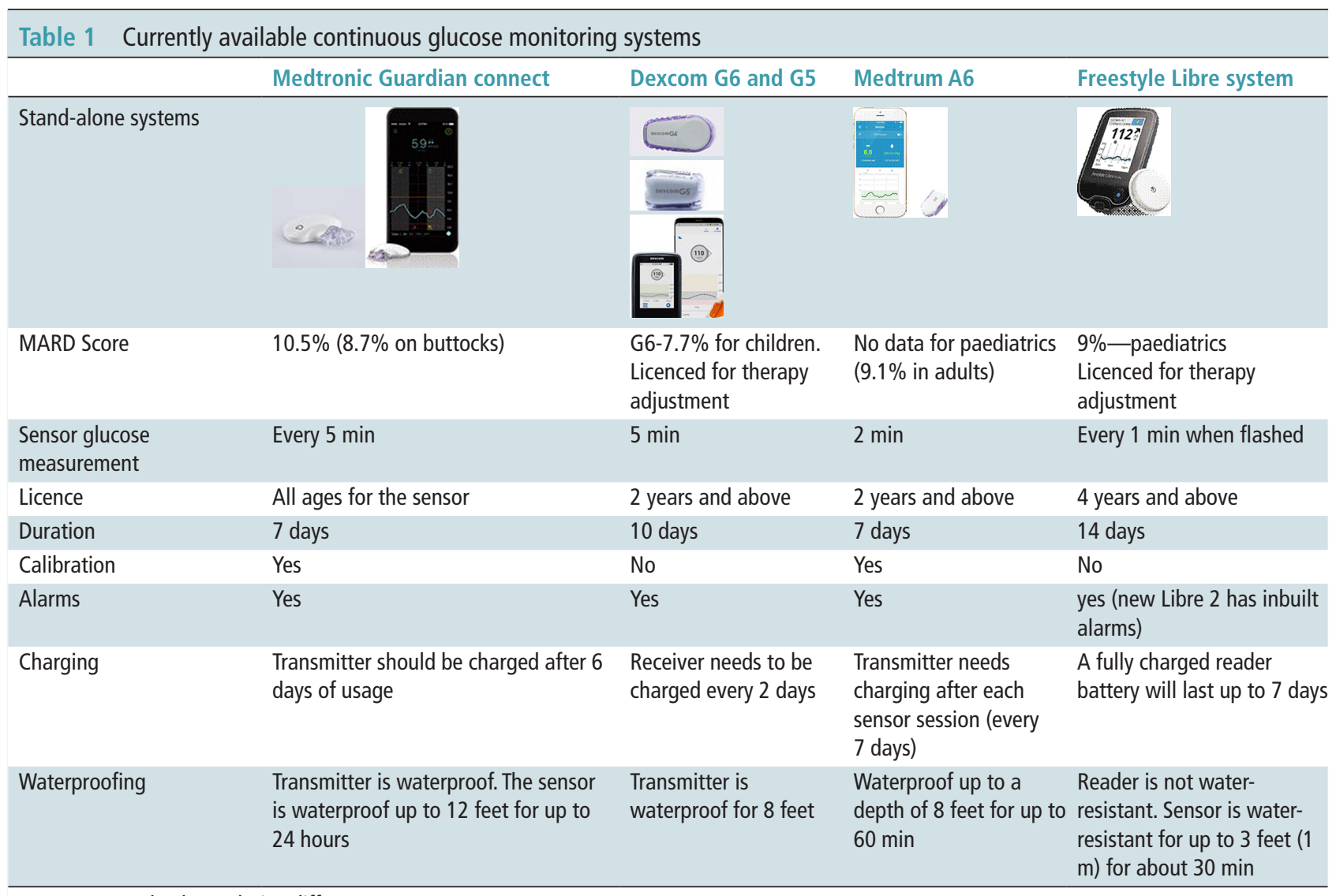

MARD, mean absolute relative difference. 


\section{Differences - plasma vs sensor}

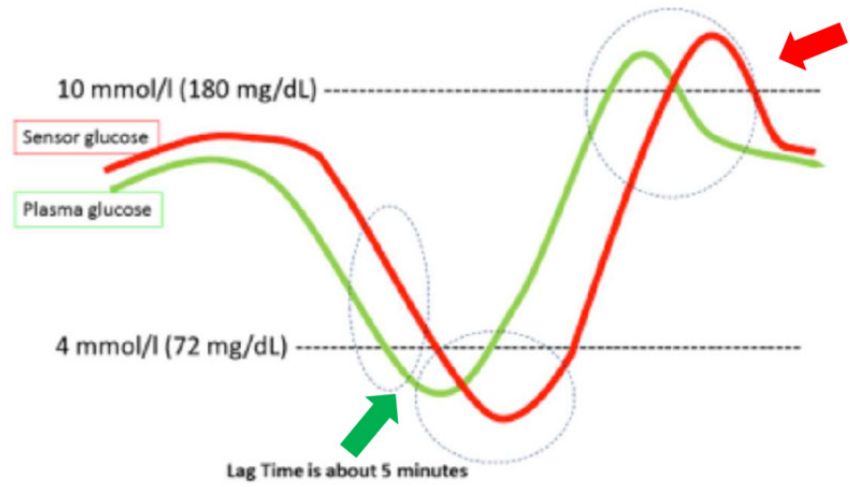

If values are falling rapidly, the blood glucose value might initially be lower than the sensor reading (see diagram) If the values are rising rapidly the blood glucose value might be higher than the sensor reading but then the sensor reading will go higher than the blood glucose value, (see diagram)

Figure 2 Diagrammatic representation of lag time.

displayed along with an arrow pointed upwards. You are not sure how to interpret this.

There are some important concepts you need to remember while looking after CYP using CGM devices and making treatment decisions

1. Lag time: It is important to remember that CGM measures interstitial glucose rather than BG. Interstitial glucose levels are dependent on the flow of glucose according to the concentration gradient between the vascular and interstitial space. The difference in glucose levels in the two compartments leads to the concept of 'lagtime'. ${ }^{4}$ The lag time is most pronounced when BG levels are changing rapidly. This concept is important to remember when considering hypoglycaemia management; the sensor reading might not pick up hypoglycaemia and lead to delayed treatment. Similarly, sensor glucose levels might not rise as rapidly as BG leading the user to repeat treatment unnecessarily (figure 2).

2. Trend arrows: CGM also detects interstitial glucose changes over time. As a result, the CGM display screen reports the glucose reading and a trend arrow. This arrow determines the rate of rise or fall of glucose. Each system has its own arrow system to display specific rates of change of sensor glucose levels. The rate of change depicted by the trend arrows helps us to predict glucose levels in the next $20-30$ min. This aids in making treatment decisions and helps avoid hypo/hyperglycaemia. Figure 3 outlines trend arrows showing the rate of change in glucose levels for different CGM systems. The insulin dosing for mealtime and corrections should be adjusted according to trend arrows. The Association of Children's Diabetes Clinicians has designed a stepwise guide that gives advice on how to alter insulin dosage based on trend arrows ${ }^{5}$ (figure 3).

3. Accuracy: Mean absolute relative difference (MARD) is the metric used to assess the accuracy of CGM systems. The mean difference between interstitial glucose and reference BG readings is presented as the MARD. A MARD of less than $10 \%$ is considered accurate enough to make treatment decisions so that an insulin bolus can

\begin{tabular}{|c|c|c|c|c|c|}
\hline Medtronic & Dexcom & Libre & $\begin{array}{c}\text { Change in } \\
\text { glucose } \\
(\mathrm{mmol} / \mathrm{l}) \text { in } \\
15 \text { mins }\end{array}$ & Description & Insulin dose adjustment during mealtime \\
\hline & $\rightarrow$ & $\rightarrow$ & $0-0.8$ & Stable & Give usual mealtime insulin \\
\hline$\downarrow$ & У & $y$ & $0.8-1.7$ & Falling slowly & Give $10 \%$ less than usual mealtime insulin \\
\hline$\downarrow \downarrow$ & $\downarrow$ & $\downarrow$ & $1.7-2.5$ & Falling quickly & Give $20 \%$ less than usual mealtime insulin \\
\hline$\downarrow \downarrow \downarrow$ & $\downarrow \downarrow$ & & $>2.5$ & Falling rapidly & Give $20-30 \%$ less than usual mealtime insulin \\
\hline$\uparrow$ & $\pi$ & $\pi$ & $0.8-1.7$ & Rising slowly & Give $10 \%$ more than usual mealtime insulin \\
\hline$\uparrow \uparrow$ & $\uparrow$ & $\uparrow$ & $1.7-2.5$ & Rising quickly & Give $20 \%$ more than usual mealtime insulin \\
\hline 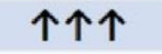 & $\uparrow \uparrow$ & & $>2.5$ & Rising rapidly & Give $20-30 \%$ less than usual mealtime insulin \\
\hline
\end{tabular}

\section{Insulin dose adjustments for trend arrows for various CGM devices}

Figure 3 Trend arrows for various continuous glucose monitoring devices and mealtime inslin does adjustments based on the arrows. 
Table 2 Advantages and barriers of using continuous glucose monitoring

\begin{tabular}{ll}
\hline Advantages & Disadvantages \\
\hline $\begin{array}{l}\text { Increased parental confidence about } \\
\text { child's safety particularly in those } \\
\text { with hypoglycaemia unawareness }\end{array}$ & $\begin{array}{l}\text { Sensor site skin irritations or } \\
\text { adhesive problems }\end{array}$ \\
$\begin{array}{l}\text { Decreased parental worry and } \\
\text { improved sleep and quality of life }\end{array}$ & $\begin{array}{l}\text { Alerts and alarms causing } \\
\text { disruption and alarm fatigue }\end{array}$ \\
$\begin{array}{l}\text { Reduced need for finger-prick BG } \\
\text { monitoring }\end{array}$ & $\begin{array}{l}\text { Lost signal resulting in data } \\
\text { gaps }\end{array}$ \\
$\begin{array}{l}\text { More time spent in target glucose } \\
\text { range-potential to improve }\end{array}$ & $\begin{array}{l}\text { Too much information and } \\
\text { data generated and difficulty in }\end{array}$ \\
glycaemic control & interpreting it \\
$\begin{array}{l}\text { More data to inform diabetes } \\
\text { management decisions and the } \\
\text { ability to be connected to a pump } \\
\text { (sensor augmented pump therapy } \\
\text { and closed-loop systems) }\end{array}$ & $\begin{array}{l}\text { Lack of availability to everyone } \\
\text { due to cost }\end{array}$ \\
\hline
\end{tabular}

be calculated from a CGM sensor reading, rather than a capillary finger prick. Dexcom G6 and FreeStyle Libre sensors have MARD of $9 \%$ and are licenced to make treatment decisions. ${ }^{6-8}$ For a sensor with MARD higher than $10 \%$, the recommendation is to check BG before treatment decisions about treating hypoglycaemia or giving insulin are made. The accuracy of the sensor is also dependent on the BG range with reduced accuracy typically in hypoglycaemic and hyperglycaemic range. It is therefore advisable to check BG with finger prick testing when levels are falling or low.

4. Other considerations when using CGM devices: Most CGM systems make use of the enzymatic reaction between glucose and glucose oxide to measure interstitial glucose levels (table 2). Paracetamol (both oral and intravenous) caused falsely elevated readings in the previous Dexcom G4 and G5 sensors and Medtronic sensors. ${ }^{9}$ Newer Dexcom G6, guardian 3 sensors and FreeStyle Libre have an acetaminophen blocker that prevents this interference at therapeutic doses of paracetamol. Clinicians should be mindful that if sensors' readings are unusually high, levels should be confirmed with fingerprick BG testing. The direct pressure on the CGM site can also cause falsely low sensor readings due to reduced tissue perfusion $^{10}$

CYP who wear a CGM device do not routinely need to check their BG readings with finger prick tests. However, they still need to make sure they calibrate their sensor as per manufacturer's instructions (table 1). It is also advisable to check BG if CGM readings do not match with clinical symptoms, for example, if a child is feeling symptoms and showing signs of hypoglycaemia but sensor readings are above the hypoglycaemic range. Not all devices are licenced to make treatment decisions. Users of those devices must check their BG before making any decisions about insulin administration. If in doubt, users must confirm with a BG test. Advantages and barriers of using CGM devices have been summarised in Table 2

\section{Case 2}

Noah is a 10 -year-old boy with Type 1 diabetes. He has been referred to a general paediatric clinic for headaches. While reviewing him, you ask his parents about his glycaemic control and last HbA1c. They tell you that they do not rely on HbA1c as Noah has haemoglobinopathy but he uses Freestyle Libre and you can look at his ambulatory glucose profile (AGP) to get an idea of his control.

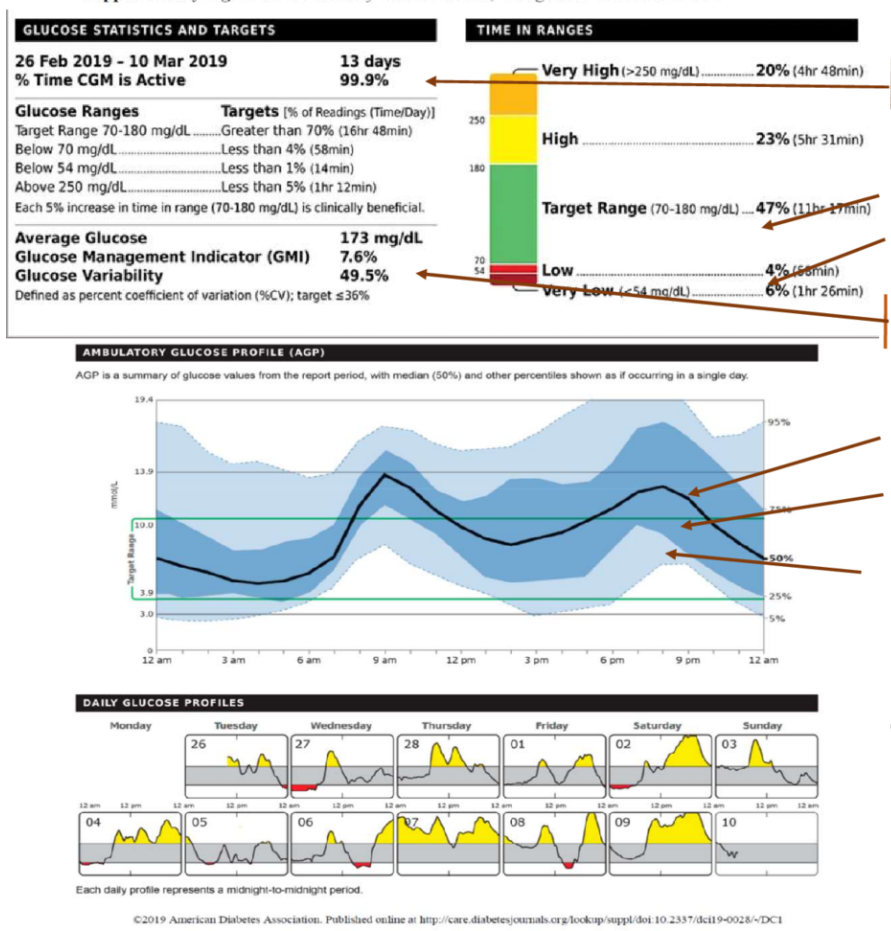

Ambulatory Glucose profile (AGP) report is displayed for 14 days of sensor wear. It correlates well to 3 months of *CGM data

CGM is active $99.9 \% \%$ of time. Recommendation is for min $70 \%$ usage (10 days) for reliable data

Time in range (TIR)- aim is to slowly increase time spent in range. TIR (3.9-

$10 \mathrm{mmol} / \mathrm{l}$ ) of $70 \%$ correlates to $\mathrm{HbA} 1 \mathrm{c}$ of $53 \mathrm{mmol} / \mathrm{mol}$

Aim for low $(<3.9 \mathrm{mmol} / \mathrm{l})$ to be limited to $<5 \%$ and very low

$(<3.0 \mathrm{mmol} / \mathrm{l})$ to be $<1 \%$

Glucose Management Indicator (GMI)- Provides with estimated HbA1c Glucose variability (GV)- refers to how much the glucose readings varies from mean or median glucose. Low GV indicates stable glucose profile

Ambulatory glucose profile: The solid line is the median or $50 \%$ line; half of all glucose values are above and half are below this value.

The 25th and 75 th percentile curves shaded in dark blue represent the interquartile range or $50 \%$ of all values and are a good visual indicator of the degree of GV.

The dashed outer lines (the 10th to 90th percentile curves) in light blue indicate that only $10 \%$ of glucose readings were above or below these value

Graph showing daily data. Each daily profile represents midnight to midnight data

Figure 4 Example of an AGP (ambulatory glucose profile). 
Table 3 Current commercial hybrid closed-loop systems

Medtronic 670G-Guardian 3

sensor

Medtronic 780G-Guardian 3

Tandem t:slimX2-Dexcom G6-

CamAPS FX DanaRS-Dexcom G6

sensor

\begin{tabular}{|c|c|c|c|}
\hline Hybrid closed-loop systems & (1) & mex & $\therefore$ \\
\hline Integrated pump & 670G, 780G (coming soon) & Tandem t:slimX2 & Dana RS Pump \\
\hline Sensor & Guardian 3 & Dexcom G6 & Dexcom G6 \\
\hline Number of finger prick tests & 4 to 6 a day, may be less for $780 \mathrm{G}$ & Rarely (Factory calibrated) & Rarely (Factory calibrated) \\
\hline Licence & 7 years and above & 6 years and above & 1 year and above \\
\hline $\begin{array}{l}\text { Compatible downloading } \\
\text { software }\end{array}$ & $\begin{array}{l}\text { Carelink } \\
\text { Manual downloading required for } \\
670 \text { G. Automated app compatibility } \\
\text { with } 780 \text { G }\end{array}$ & $\begin{array}{l}\text { Clarity (sensor data), Diasend, Manual } \\
\text { downloading of pump required }\end{array}$ & $\begin{array}{l}\text { Diasend } \\
\text { Automated download }\end{array}$ \\
\hline Waterproofing & $\begin{array}{l}\text { Pump and transmitter are } \\
\text { waterproof. Sensor is waterproof up } \\
\text { to } 12 \text { feet for up to } 24 \text { hours }\end{array}$ & $\begin{array}{l}\text { Pump is waterproof for up to } 3 \\
\text { feet for } 30 \text { min and transmitter are } \\
\text { waterproof for } 8 \text { feet }\end{array}$ & $\begin{array}{l}\text { Pump is fully waterproof (IPX8) and } \\
\text { transmitter is waterproof for } 8 \text { feet }\end{array}$ \\
\hline
\end{tabular}

Adapted from: Leelarathna L, Choudhary P, Wilmot EG, Lumb A, Street T, Kar P and Ng SM (2020). Hybrid closed-loop therapy: Where are we in 2021? Diabetes Obes Metab. Advance online publication. https://doi.org/10.1111/dom.14273.

\section{WHAT IS AGP?}

It is a summary report that includes useful information for the clinician to make practical clinical decisions. An international expert panel has provided guidance on CGM metrics as a standard for assessing glycaemic control. ${ }^{11}$ They concluded that retrospective analysis of CGM data using a standardised AGP should be used to help patients set their glycaemic goals. CGM metrics such as time in range (time spent between 3.9 and $10 \mathrm{mmol} / \mathrm{L}$ ) can be used as a clinical target and an outcome measure together with HbA1c. NICE recommends achieving a target $\mathrm{HbA} 1 \mathrm{c}$ of $<48 \mathrm{mmol} / \mathrm{mol}$ in CYP in the UK. Seventy per cent of time spent in range (TIR) correlates with $\mathrm{HbA} 1 \mathrm{c}$ of $53 \mathrm{mmol} / \mathrm{mol}(7.0 \%)$. An increase in time spent in the range of 2.4 hours $(10 \%)$ corresponds to a decrease in HbA1c of approximately $5 \mathrm{mmol} / \mathrm{mol}(0.5 \%)$. AGP profile also calculates a glucose management indicator (GMI). GMI is an estimate of HbA1c based on 14 or more days of glucose data. Figure 4 shows an example of an AGP.

\section{Why do we need a new metric?}

HbA1c has been the gold standard for long-term monitoring of Type 1 diabetes since Diabetes Control and Complications Trial in the 1990s showed that intensive diabetes management reduced the incidence and progression of long-term microvascular complication in adolescents and adults with Type 1 diabetes. ${ }^{12}$ There are however limitations in using $\mathrm{HbA} 1 \mathrm{c}$ alone to guide strategies for improving diabetes control. HbA1c cannot provide information on glycaemic variability on a day to day basis. ${ }^{13}$ Regular hypoglycaemic episodes will lead to low HbA1c without providing the true picture of glycaemic control. Iron deficiency anaemia, haemoglobinopathies and ethnicity also affect HbA1c. ${ }^{14}$

\section{Future of diabetes management-hybrid closed-loop systems}

The future of diabetes management is with complete automation of the treatment 'loop'. The loop consists of a glucose monitoring device (BG metre or CGM), a system to calculate the insulin dose required and a device to deliver the insulin (an insulin pen or a pump). Closed-loop systems are based on CGM-pumpalgorithm which automatically calculate insulin doses. Currently, hybrid closed-loop systems are available where a part of treatment still requires manual intervention. These pumps have inbuilt technology such that they can be linked to sensors and automatically adjust the basal dose. Insulin boluses for meals (carbohydrates) must still be delivered by users. Medtronic 670G with guardian connect CGM sensor, Tandem t: slim X2 with Dexcom G6 sensor and the DanaRS pump with CamAPS Fx systems are currently available in the UK. Hybrid closed-loop therapy has significantly improved the percentage of TIR and HbA1c outcomes in CYP living with diabetes. ${ }^{15}$ Table 3 lists all the main hybrid closed-loop systems available in the UK.

\section{CONCLUSION}

The use of technology for managing diabetes is advancing rapidly. It has the potential to improve the management and quality of life for people with 
diabetes. The new technologies help in individualising care, thus helping us to reduce the disease burden. With improved glucose monitoring, patients can improve their glycaemic control without increasing the risk of hypoglycaemia. Expansion of the use of technology will see more and more people living with diabetes, wearing CGM systems, pumps and systems with integrated algorithms to automatise their diabetes management. Healthcare professionals must keep up to date with these advances to be able to fully support and provide optimal care for their patients.

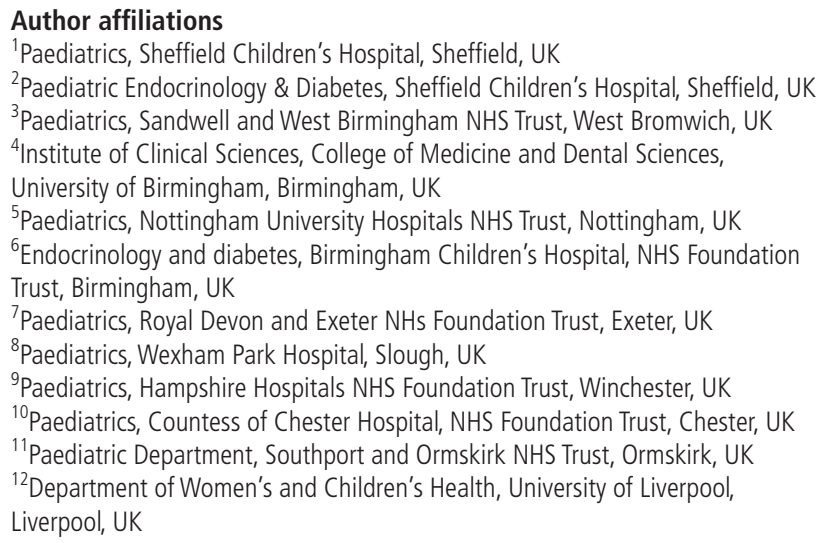

\section{Twitter Sze May Ng @mayng888}

Contributors AS, SMN and NW conceived the idea about writing CGM themed paper. AS, SMN wrote the first draft. JCA, NW and CM provided with the images and technical insights. They also reviewed the first draft. EW, MK, JD, FR and AT reviewed the draft and suggested changes. All authors are committee members of ACDC (Association of Children's Diabetes Clinicians) and have contributed to the ACDC CGM guideline. They have also trained paediatrician all over the country in using CGM devices, interpreting data and helping patients in clinical settings.

Funding The authors have not declared a specific grant for this research from any funding agency in the public, commercial or not-for-profit sectors.

\section{Competing interests None declared.}

Patient consent for publication Not required.

Provenance and peer review Commissioned; externally peer reviewed.

Open access This is an open access article distributed in accordance with the Creative Commons Attribution Non Commercial (CC BY-NC 4.0) license, which permits others to distribute, remix, adapt, build upon this work noncommercially, and license their derivative works on different terms, provided the original work is properly cited, appropriate credit is given, any changes made indicated, and the use is non-commercial. See: http://creativecommons.org/ licenses/by-nc/4.0/.

\section{ORCID iDs}

Astha Soni http://orcid.org/0000-0002-2586-4337

Neil Wright http://orcid.org/0000-0003-0524-594X

Juliana Chizo Agwu http://orcid.org/0000-0002-8593-187X

Sze May Ng http://orcid.org/0000-0002-3449-0541

\section{REFERENCES}

1 NG18. Diabetes (type 1 and type 2) in children and young people: diagnosis and management. NICE, 2015.

2 Haller MJ, Stalvey MS, Silverstein JH. Predictors of control of diabetes: monitoring may be the key. J Pediatr 2004;144:6601.

3 Vigersky RA. The benefits, limitations, and cost-effectiveness of advanced technologies in the management of patients with diabetes mellitus. J Diabetes Sci Technol 2015;9:320-30.

4 Chen C, Zhao X-L, Li Z-H, et al. Current and emerging technology for continuous glucose monitoring. Sensors 2017;17:182.

5 Ag group. A Practical Approach to the management of continuous glucose monitoring (CGM)/ Real-Time Flash GlucoseScanning (FGS) in Type 1 Diabetes Mellitus in Children and young people under 18 years of age, 2017.

6 Shah VN, Laffel LM, Wadwa RP, et al. Performance of a Factory-Calibrated real-time continuous glucose monitoring system utilizing an automated sensor applicator. Diabetes Technol Ther 2018;20:428-33.

7 Bailey TS. Clinical implications of accuracy measurements of continuous glucose sensors. Diabetes Technol Ther 2017;19:S$51-4$.

8 Ajjan RA, Cummings MH, Jennings P, et al. Accuracy of flash glucose monitoring and continuous glucose monitoring technologies: implications for clinical practice. Diab Vasc Dis Res 2018;15:175-84.

9 Maahs DM, DeSalvo D, Pyle L, et al. Effect of acetaminophen on CGM glucose in an outpatient setting: Figure 1. Diabetes Care 2015;38:e158-9.

10 Forlenza GP, Argento NB, Laffel LM. Practical considerations on the use of continuous glucose monitoring in pediatrics and older adults and Nonadjunctive use. Diabetes Technol Ther 2017;19:S-13-20.

11 Battelino T, Danne T, Bergenstal RM, et al. Clinical targets for continuous glucose monitoring data interpretation: recommendations from the International consensus on time in range. Diabetes Care 2019;42:1593-603.

12 The DCCT Research Group. The effect of intensive treatment of diabetes on the development and progression of long-term complications in insulin-dependent diabetes mellitus. The diabetes control and complications trial Research Group. The New England journal of medicine 1993;329:977-86.

13 Gorst C, Kwok CS, Aslam S, et al. Long-Term glycemic variability and risk of adverse outcomes: a systematic review and meta-analysis. Diabetes Care 2015;38:2354-69.

14 Beck RW, Connor CG, Mullen DM, et al. The Fallacy of Average: How Using $\mathrm{HbA}_{1 \mathrm{c}}$ Alone to Assess Glycemic Control Can Be Misleading. Diabetes Care 2017;40:994-9.

15 Karageorgiou V, Papaioannou TG, Bellos I, et al. Effectiveness of artificial pancreas in the non-adult population: a systematic review and network meta-analysis. Metabolism 2019;90:20 30. 